\title{
THE BUSINESS WOMEN'S ASSOCIATION OF UZBEKISTAN: A QUALITATIVE STUDY OF THE EMERGENCE AND POTENTIAL INFLUENCE OF WOMEN'S LEADERSHIP IN CENTRAL ASIA
}

\author{
Kimberly Millier \\ Grand Canyon University, Phoenix, AZ \\ Patty-Jo Bellamy \\ Kaplan University, Ft. Lauderdale, Florida
}

\begin{abstract}
This phenomenological study used the first five steps of a modified van Kaam method by Moustakas in conjunction with semistructured interviews to explore the lived experiences of a sample of front line leaders of the Business Women's Association of Uzbekistan (Tadbikor Ayol) that operates in an environment hostile to women in general and to businesswomen specifically. The association, founded in 1991 continues to develop and mentor the women entrepreneurs of Uzbekistan. Discovering the factors that influence the viability and sustainability of the BWA as it continues to operate in a challenging cultural and political environment and the applicability of the factors to Central Asia was the focus of this study. The results of the research identified five themes: 1) leadership style; 2) seminars and skill building activities; 3) peer and family relationships; 4) financial support; and 5) government relations.
\end{abstract}

Keywords: Business Women’s Association, Central Asia, Synergistic, Transformational, Uzbekistan

\section{INTRODUCTION}

Women constitute approximately $50 \%$ of the population of the world (World Population Prospects, 2006). To exclude or limit women's economic participation is to deny the potential of half of the world's human capital, and marginalizing women may adversely affect a country's economic growth and quality of life of the population as a whole (Ndemo \& Maina, 2007). The cost of gender discrimination is increased poverty, a stagnant economy, a misrepresentative governing structure, and a lower standard of living (Ndemo \& Maina, 2007). According to Cooper and Traugott (2003), "Support for women is not only a moral imperative but improvements in the conditions for women may have a significant and positive impact on long-term security” (p. 61).

The subjugation of women is not a new phenomenon, nor is it restricted to any particular country, region, religion, or culture. The women of Uzbekistan and other Central Asian countries have a history of subjugation; in contrast, the Soviet era, from 1924 to 1991, was a time of governmental support for the women of the region (Saidazimova, 2005). The policy of the Soviet state was to instill equal rights for women in society and under the law by establishing a system of quotas for equal participation by women in education, the workforce, politics, and the military (Saidazimova, 2005).

When the Soviet Union collapsed in 1991 and Uzbekistan gained independence, the quotas that helped ensure women's participation in society, particularly in the workforce, disappeared (Saidazimova, 2005). In the absence of institutional support, the women of Uzbekistan took advantage of the growth in the fledgling market economy to forge a significant presence in the bazaars and establish business entities specializing in providing goods and services (Women Economic Empowerment, 2007). From this pool of women entrepreneurs emerged a group of 12 women who came together to establish the Business Women's Association of Uzbekistan (BWA) under the registered name of Tadbirkor Ayol. The BWA is a non-governmental organization (NGO) established in 1991 to assist women business owners or individuals who wanted to become business women (Women Economic Empowerment, 2007). Support for the organization's operations comes from donations, grants, membership fees, and the government of Uzbekistan (Association of Business Women of Uzbekistan, 2007).

A revival of Uzbek nationalism that paralleled the country's independence in 1991 prompted a return to Muslim traditional and patriarchal norms and resulted in the erosion of support for Uzbek women to participate in the market economy (Saidazimova, 2005). Although the Uzbek government attempted to support women's rights and gender equality through legislation, mistrust of the NGO sector increased and extended to the BWA (Association of Business Women of Uzbekistan, 2007). The number of NGOs in Uzbekistan numbered approximately 8,570 prior to 2005. By mid-2007, fewer than $50 \%$ of the NGOs not affiliated with the government existed (NGO Sustainability, 2007). The BWA survived the 2005 to 2007 purge and continues to support the efforts of the country's women entrepreneurs. By providing a supportive environment for achieving economic independence, access to education, and an understanding of the laws that govern individual rights, the BWA may influence the development of Uzbek society.

Studying a business women's association in a Muslim 
country is unique. Discovering the factors that influence the viability and sustainability of the BWA as it continues to operate in a challenging cultural and political environment may provide a better understanding of the relationship of the factors to leadership methodology. Once developed, the leadership methodology may lead to the formation of a leadership design that can be modified and applied to businesswomen's associations and disadvantaged organizations in other developing countries.

The specific problem was to discover and identify the unknown factors and barriers that influence the viability and sustainability of the BWA. This qualitative, phenomenological study using the modified Van Kamm method (Moustakas, 1994) explored the lived experiences of a subset of the members of the BWA to understand the factors responsible for the organization's viability and sustainability. The BWA operates in a patriarchal, predominately Muslim society and a political environment that is overtly supportive but lacks commitment to the disempowered women of the country. Despite the challenges, the BWA is viable and sustainable, but the factors influencing the organization's viability and sustainability are unknown.

\section{REVIEW OF THE LITERATURE}

During the first decade of Soviet rule, few women worked outside their home. Access to modern education, including higher education, was limited. "Whereas in the beginning of the 1990s nearly half of all Uzbek women worked, 49 percent of high school graduates were girls and the share of women in higher administrative and management positions amounted to 17.5 percent” (Tokhtahodjaeva, 2000, p. 51).

The governments of most of the Central Asian republics transitioned quickly to the new market economy. Uzbekistan pursued a different path; a journey marked by a policy of transitioning slowly toward "an independent political path and an Uzbek cultural renewal” (Gleason, 2006, p. 55). During the transition, employment decreased significantly, and the majority of women lost their jobs, social benefits, and governmental support for working in the public sector (Welter, et al., 2006). For the women of Uzbekistan, the postSoviet era has been a struggle for survival and dignity (Marney, 2005). Economically, the transition to a market economy resulted in a decline in living standards for the majority of Uzbekistan's population, but affected women to a greater degree (Welter, et al., 2006). With the return to Muslim traditionalism, the support for women participating in a market economy eroded (Saidazimova, 2005) and a mistrust of the NGO sector increased, resulting in a rapid decrease in the number of NGOs (NGO Sustainability, 2007). The WBA was able to survive this period and continues to support women in business.

The first businesswomen's association in Uzbekistan was the BWA (Tadbirkor Ayol) founded in 1991 (Association of Businesswomen of Uzbekistan, 2007). The executive director recruited a group of 11 like-minded women and together they designed the structure, vision, goals, and objectives of the BWA. The BWA team constructed a flat organization and provided leadership to the entity while growing the membership, providing services, mentoring a new cadre of leaders, and establishing relationships with government and business leaders (Marnie, 2005). The mission of the BWA is to create favorable conditions for women's participation in the process of market relation's development, support entrepreneurial initiatives, protect women's rights, and represent members' interests (Alimbekova, 2002). The main activities of the BWA are business counseling, training, micro credit programs, lobbying, and advocating for a role for women in business and society (Alimbekova, 2002). The BWA has approximately 4,000 members as of 2009. The organization's headquarters is in Tashkent with 116 branches (registered and not registered) throughout the country including Tashkent, the Tashkent Region, and Bukhara (G. Makhmudova, personal communication, June 9, 2009). The BWA is a member of the World Business Professional Women's Organization and the Assembly of Commonwealth of Independent States (CIS) Women Non-Governmental Organizations (Alimbekova, 2002).

\section{THEORETICAL FRAMEWORK}

For the purposes of this study, two theories of leadership received close examination: transformational and synergetic. Bass (1998) and Ardichvili and Kuchinke (2002) provided empirical evidence that even though not all leadership theories are directly transferable to all cultures, transactionaltransformation leadership is applicable across cultures, particularly in countries once belonging to the Soviet Union. Synergetic leadership theory is gender inclusive and emphasizes the interaction of "leadership behavior; organizational structure; external forces; and attitudes, beliefs, and values” (Irby, et al., 2002, p. 304). The inclusiveness, flexibility, and gender-neutral properties of synergetic leadership give the theory the potential for applicability in business environments worldwide (Holtkamp, et al., 2007).

\section{Transformational Leadership}

The GLOBE research project conducted in 1999 included 62 countries and all continents. Research findings verified that all countries, but particularly developing countries, preferred the charismatic, transformational leadership style (Hartog, et al., 1999). The attributes of transformational leaders most valued by followers in developing countries included vision, relationships, the ability to motivate others, and the skills to guide the organization during changing times (Hartog, et al., 1999). Other valued attributes of transformational leadership emphasized in the GLOBE study included encouraging followers to find solutions to problems and the ability and willingness to communicate, motivate, and encourage others (Hartog, et al., 1999). Based on the visible role of leaders in developing countries and their influence on organizational performance, a logical theoretical basis for the discovery of the factors influencing the viability and sustainability of the BWA may be transformational leadership theory.

\section{Synergetic Leadership}

There are five problems perpetuated by theories in leadership that are male-based. The first problem is that leadership theory does not fully embrace female attributes, such as nurturing, empowerment, and collaboration. The second problem is leadership training is male focused and not necessarily relevant to all learners. The third problem is education perpetuates barriers to women's efforts to reach leadership positions. The fourth problem is stereotypical 
norms, such as the need for women to adopt masculine leadership styles, are promoted within organizations. The fifth and last problem is that women continue to have outsider status that leads to their isolation and exclusion (Irby, et al., 2002).

The Synergistic Leadership Theory (SLT) "is a gender inclusive theory which addresses the female perspective and which includes attributes, experiences, and abilities inherent in male, as well as female, leaders” (Holtkamp, et al., 2007, p. 5). The theory is tetrahedral with four constructs, 1) organizational structure; 2) leadership behavior; 3) beliefs and attitudes; and 4) external forces (Holtkamp, et al., 2007).

Organizational structure is a collection of the characteristics and operations of organizations. Within the SLT leadership model, the characteristics of organizational structure are on a continuum "ranging from open, feminist organizations to bureaucratic ones...characterized by division of labor, rules, hierarchy of authority, impersonality, and competence; while feminist organizations feature participative decision making, systems of rotating leadership, promotion of community and cooperation, and power sharing” (Holtkamp, et al., 2007, p. 7). Feminist theory reinforces this characterization of the organization by stating that men and women have innate differences demonstrated by the fact that women have greater compassion than men who tend to focus more on financial gain (Cron, et al., 2006).

The limited inclusion of both genders in most transformational leadership studies “has left women's voices and experiences as transformational leaders and as followers largely unheard and uncharted” (Kark, 2004, p. 168). Studies that focus on women's viewpoints, using more qualitative research methods and application of SLT are likely to "provide critical descriptions and unique interpretations that can shed new light on the ways we understand transformational leadership” (Kark, 2004, p. 168). Combining transformational leadership with synergetic leadership in this study may help identify the factors influencing the viability and sustainability of the BWA.

\section{METHODOLOGY}

The purpose of this qualitative, phenomenological study was to discover the factors that influence the viability and sustainability of the Business Women's Association (BWA) of Uzbekistan by examining the lived experiences of a subset of the association's managers and members. The results of the study provided a contextual framework for future study of the transferability of the identified factors. The longevity, continued viability, and sustainability of the BWA is a phenomenon within a Muslim culture and business environment in which women are supplementing or substituting the traditional nurturing role of wives and mothers by engaging in entrepreneurial and professional business pursuits outside the home (Kamp, 2006). This phenomenon was worthy of further exploration and formed the basis of the study.

The methodology for the research study was qualitative. A qualitative research methodology was appropriate for this study, since a holistic or systems perspective is best suited for providing insight, discovering unexpected outcomes, and identifying areas for further study (Creswell, 2005). Data were collected using general, open-ended questions that allowed the participant(s) to respond without the hindrance of structural constraints, and the information took the form of words gathered from interviews of a number of individuals or sites (Creswell, 2005). The goal of the study was to seek an understanding of the phenomenon, as it was lived (Wilson \& Washington, 2007). A phenomenological research design was appropriate because the subjective perspective and its effect on individuals is an emphasis in a phenomenological study (Wilson \& Washington, 2007).

The population selected for this study was the BWA's approximately 4,000 members and offices located in the 13 regions of Uzbekistan (Association of Businesswomen of Uzbekistan, 2007). The sample under investigation was the membership of the BWA in three locations. The sites chosen included the headquarters and largest BWA office in Tashkent, Uzbekistan's capital city; the Tashkent Region, a part of the country's agricultural region; and Bukhara, in the dry desert area of western Uzbekistan (MacLeod \& Mayhew, 2008). The study was confined to individual interviews of managers and members of the organization at each of the three sites for a minimum of 18 participants. Snowball sampling provided other content rich respondents, which increased the number of respondents to 24. Only current members and managers of the BWA were considered, and the goal was to have participants who had a minimum of three years as members of the BWA and a sample with a mix of ages, ethnicities, and lengths of membership with the organization. The BWA nominated two managers and eight participants for each site and included a brief biographical description of each nominee. The three interview sites reflected different aspects of the working environment of the BWA (MacLeod \& Mayhew, 2008).

The interviews were recorded and underwent translation by an Uzbek-based translator and a translator in the United States. After translation, the data underwent phenomenological reduction and triangulation using NVivo 8.0. Questions sought to discover the attributes of the BWA leadership and organizational structure. Other questions pursued included how the organization's management influences cultural barriers, gender stereotypes, and legislative challenges to the benefit of the members.

\section{PRESENTATION AND ANALYSIS OF DATA}

The qualitative research methodological study sought to answer the central question, "What are the factors influencing the viability and sustainability of the Business Women's Association of Uzbekistan?" Three research questions provided perspective and insight to the exploration of the central question: (1) How does the BWA address issues such as cultural barriers, gender stereotypes, and legislative challenges on behalf of the members?; (2) What factors influence the viability of the organization?; and (3) What factors influence the sustainability of the organization?

Eleven interview questions were developed to support the research questions and were designed to give greater depth and a sequential flow to the interview process. Demographic data gathered from the 24 participants included location, business type, age, marital and dependent status, education, and length of membership. The ages of the participants ranged from 29 to 66 and represented an average age of 47 . The majority of respondents (17 out of 24) have a college degree, with managers slightly outpacing the percentage of members with a college degree. All participants were married and all 
but one had children. Specific steps taken before, during, and after the interviews helped to ensure accurate and representative collection of data. The interview focused on the respondents' lived experiences and perceptions rather than theory, and interviewees were allowed to talk freely with minimal prompting.

\section{Research Outcomes}

The three research questions and the supplemental eleven interview questions assigned a number that corresponded to the order in which they were asked. All questions were designed to explore the central question: What are the factors influencing the viability and sustainability of the Business Women's Association of Uzbekistan (Tadbirkor Ayol)?

Research question one. How does the BWA address issues such as cultural barriers, gender stereotypes, and legislative challenges on behalf of the members? Several participants consistently identified financial issues as a challenge. In addition to providing grant writing seminars and seminars on how to seek and secure credit, the BWA established Tashkent's first credit union and was able to offer low-interest loans to its members. Several of the participants commented about the support they receive from family members but also mentioned the negative attitudes of other husbands, men, and family members regarding women, including wives, working outside the home

Research question two. The second research question was designed to identify the factors that influence the viability of the organization. Although the type of businesses run by the managers and members of the BWA varied, there were five major groupings: study and training centers, fashion design and sewing, agricultural pursuits, cooking and baking, and pharmacies. All respondents took one or more BWA seminars, particularly the four-month business planning course, prior to launching their businesses. All the women-owned businesses are small (fewer than 150 employees). Most businesses have five or fewer employees, and employment of family members is common. All respondents were graduated from high school and most have undergraduate college educations (17 of 24). Reasons for joining the BWA centered on skill building, a desire to help others, information sharing, to learn how to work for oneself, to help develop Uzbekistan, to receive moral support, to socialize with one's peers, and to gain access to low-interest loans.

Research question three. The purpose of this question was to help identify the factors that contributed to the sustainability of the organization by querying about the length and reasons for continuance of membership; challenges; reasons for success of the BWA; greatest accomplishments of the organization; and comments and experiences the participants wished to share. The average length of respondent membership was 9 years, with a range of 3 to 15 years. The primary reasons given for continued membership were acquisition of skills and knowledge, camaraderie among the membership, access to credit, and the desire to give back to the organization and other women to show appreciation for the help they received.

The predominant reason for organizational success as noted by the participants was the quality of the leaders and their leadership style (18 of 24 responses), which was described as communicative, caring, sharing, and having a "management style [that] is like that of a teacher and apprentice.” The greatest accomplishments of the organization were identified as growth, name recognition, the ability to help women establish businesses, teamwork, a caring environment, the establishment of a credit union, and the development of a strong organization powerful enough to defend the rights of women. Other comments included a statement that $15 \%$ of the craftspeople in the bazaar are members of the BWA, and the BWA has a master-apprentice program for underprivileged women and girls.

Using the NVivo 8.0 software facilitated the sorting and grouping of the data from the 24 manager-and-member interviews and the two meetings with BWA leaders. After analysis and interpretation of the data, five themes emerged: 1) leadership style; 2) seminars and skill building activities; 3 ) peer and family relationships; 4) financial support; and 5) government relations.

\section{CONCLUSION AND RECOMMENDATIONS}

The five themes derived from an analysis are explored. Each of the themes is integral to the subsections that constitute the framework of a BWA leadership model (Appendix 1) developed in the context of the five themes.

\section{Theme 1 - Leadership Style}

Responses from participants emphasized the importance of the role of the leaders of the BWA in the phenomenon of the viability and sustainability of the association. The descriptors of the leaders included experienced, energetic, well-organized, skilled, kind, understanding, compassionate, informative, ambitious, determined, ingenious, supportive, cooperative, trustworthy, sociable, proactive, and disciplined. Leaders were viewed as similar to teachers with the members as their students and were commended for sharing their knowledge, using good communication skills, being team oriented, and possessing good organizational skills.

The descriptors identified by the interviewed participants were compared to leadership theory literature to ensure correct identification of the style of the leaders of the BWA. The results of that comparison are aligned with a theory refined by Bass (1990) that leadership could be defined in the context of transactional and transformational styles. The results of the categorization were consistent with the results from the GLOBE research project that verified the charismatic/transformational leadership style was the choice of individuals and managers in countries emerging from command economies (Hartog, et al., 1999).

\section{Theme 2 - Seminars and Skill Building Activities}

The viability and sustainability of an organization is significantly dependent on identifying a target market, discovering its needs, and designing a product or products to meet those needs (Welter, et al., 2006). The BWA followed a business model to identify the target market as women with a desire to participate in Uzbekistan's market economy (Women Economic Empowerment, 2007). The products identified by the BWA included seminars, workshops, classes, and trainingthe-trainers' sessions that developed business skills (Alimbekova, 2002).

\section{Theme 3 - Peer and Family Relationships}


The majority of the businesses owned by the participants represented traditional roles that extended the nurturing role of women into the general workforce (Hutchings, 2000). The interaction with other businesswomen was viewed by the participants as necessary to evolve their businesses beyond traditional roles and was given as a reason for acquiring and retaining membership in the BWA. The data suggested that although in Uzbek society there are negative attitudes from husbands, men, and family members regarding women working outside the home, members and managers of the BWA are, in general, receiving support for their entrepreneurial activities

\section{Theme 4 - Financial Support}

A reduction of worldwide poverty is an important component of a thriving global economy (Lucy, Ghosh, \& Kujawa, 2008). Members of the Business Women's Association of Uzbekistan and other entrepreneurial women in the country seek to avoid poverty by establishing and growing businesses but have limited access to capital because of gender inequality and cultural restrictions that limit women's accumulation of assets (Chalhoub, 2009). Traditional banks limit loans to entrepreneurs and small businesses because of applicants' lack of collateral, high transaction costs, and increased risk (Maksudova, 2009). Microcredit programs, which do not require collateral, provide access to funds for women and other marginalized groups and work best in areas in which poverty is severe (Lucy, et al., 2008). Within the context of Uzbekistan, microcredit loans average \$136 with interest rates that range from $4.5 \%$ to $6.5 \%$ a month (UNDP, 2006). Filling the financial lending gap between traditional banks and microcredit programs are credit unions. Credit unions are financial cooperatives that use member savings, rather than outside capital, to finance loans and "exist to serve their members and communities" (World Council of Credit Unions, 2010, p. 1). The average loan from credit unions in Uzbekistan is $\$ 1,170$, and interest rates range from $4 \%$ to $8 \%$ per month (UNDP, 2006).

\section{Theme 5 - Government Relations}

Today, the Uzbek government's relationship with the NGO sector continues to be characterized as wary and distrustful (USAID, 2009). The leaders of BWA understand that a positive relationship with the government at all levels was needed to facilitate both planning and implementation of a NGO's mission, goals, and objectives (Chalhoub, 2009). The leaders have contacts and good relationships with individuals within the government forged during the years prior to independence (Welter, et al., 2006).

\section{IMPLICATIONS}

Leadership style was one of the five themes developed from an analysis of the data. Participant responses identified transformational with a charismatic component as descriptive of the leadership style of the BWA, which are consistent with a premise by Fraser (2008) that new and innovative organizations are often led by charismatic individuals "who demonstrate the ability to capture the imaginations and hearts of their followers” (p. 1).
Women's business organizations are in various stages of evolution throughout the world's developing countries. Although the BWA is faced with serious challenges, such as funding issues and diminishing political support from the government, the association is well developed and its leaders provide members with a wide range of services.

The similarity of the businesswomen's associations to the beliefs, attitudes, and values component of the BWA Leadership Model (below) is unknown. Many of the developing countries are Islamic as is Uzbekistan, which suggests that commonality with the beliefs, attitudes, and values component of the model may exist. Because of the similarities in the challenges facing NGOs in developing countries, including businesswomen's associations, the components encapsulated within the results of the research may be transferable and adaptable to other developing countries. The BWA Leadership Model could be used as the framework for transferring and adapting the components of the viability and transferability of the BWA to other countries.

Two theories of leadership formed the theoretical framework of the study: transformational leadership and the Synergetic Leadership Theory (SLT). Respondents of the study provided descriptors of the leadership style of the managers and leaders of the BWA that suggested a transformational leadership style with a charismatic component was pervasive in the association. The SLT is gender inclusive and emphasizes the interaction of five components, or factors: "leadership behavior; organizational structure; external forces; and attitudes, beliefs, and values" (Irby, et al., 2002, p. 304). The five themes that emerged from the data were leadership style, seminars and skill building activities, peer and family relationships, financial support, and government relations. In comparing these themes with the four components of the Synergetic Leadership Theory, similarities and differences emerged.

Figure 1 is a graphic of the factors of the Synergistic Leadership Theory (SLT). The SLT "is a gender inclusive theory which addresses the female perspective and which includes attributes, experiences, and abilities inherent in male, as well as female, leaders" (Holtkamp, et al., 2007, p. 5). The theory is tetrahedral (see Figure 1) with four constructs, 1) organizational structure; 2) leadership behavior; 3) beliefs and attitudes; and 4) external forces (Holtkamp, et al.).

Theme one, leadership style, is one of the four internal components of the model and was identified as transformational/charismatic by the respondents. The BWA's flat organizational structure, a second internal component of the model, was discussed in theme one and reflects the transformational leadership style of the association's managers. Theme one, leadership style, is one of the four internal components of the model and was identified as transformational/charismatic by the respondents. The BWA's flat organizational structure, a second internal component of the model, was discussed in theme one and reflects the transformational leadership style of the association's managers. 


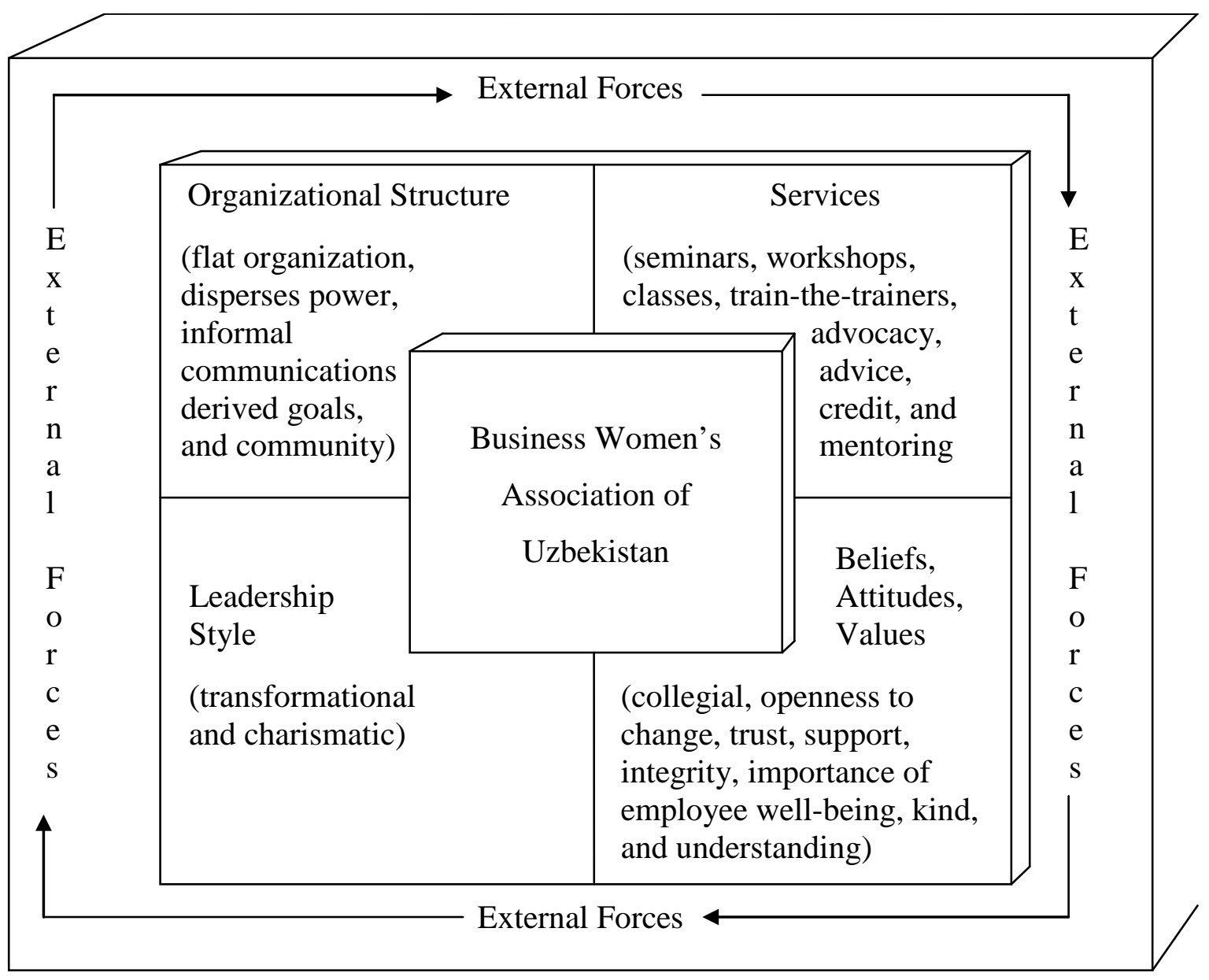

Figure 1. The BWA Leadership Model

Source “The Synergistic Leadership Theory” by B. J. Irby, J. D. Brown, and D. Trautman, 2002, Journal of Educational Administration, 40 (4), p. 313. Adapted with permission of the author.

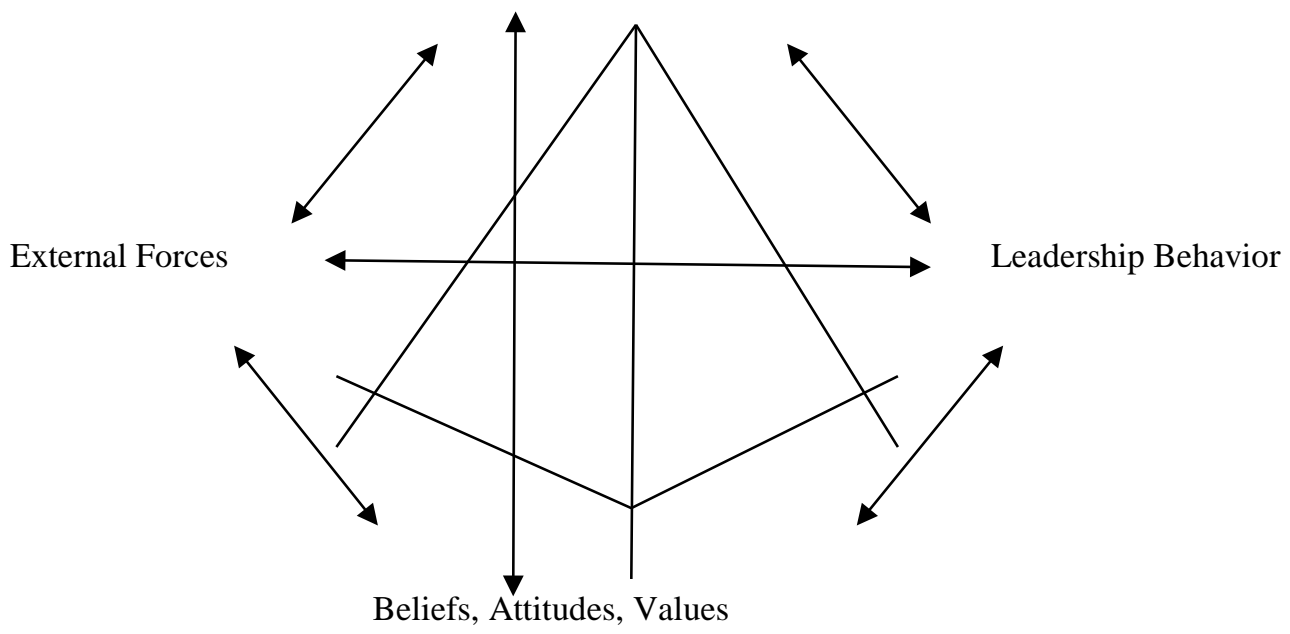

Figure 2 Synergistic Leadership Model Organizational Structure Source: Irby, et al. (2002).

The second theme, seminars and skill building activities, fits within the model's newly created internal component of services. Respondents identified services offered by the BWA as the main reason for joining and remaining as members of the BWA. The third theme of peer and family relationships fits within the internal component of beliefs, attitudes, and values. The premise of the model is that an organization, such as the BWA, is viable and sustainable if there is alignment among all five internal and external components. 


\section{Alignment and Balance of the BWA Leadership Model}

The BWA Leadership Model represents a collection of five internal and external components or factors that combine the themes that emerged from the study's data with the four factors of the SLT. The inclusion of a services component and an internal and external categorization of the components were added to the SLT model to create the BWA Leadership Model. The five components of the BWA model, when aligned, interact synergistically to form the essence of the association. The BWA is currently in alignment; a state of organizational balance that is accomplished when there is no significant disruptive interaction among the internal components or between the internal and external component categories of the model.

Interaction among the internal components of the model and between the internal and external component categories of the model is in constant motion, since the environment in which the association operates is dynamic. As long as the leadership style of the leaders, organizational structure, services, peer and family relationships, and external forces can respond to changes and challenges that emerge from the operational and external environment without disrupting the alignment of the organizational components, the association will remain in balance and the viability and sustainability of the BWA will continue. An example of a response to a challenge that had the potential to create misalignment of the organization and affect the viability and sustainability of the BWA occurred when the association lost most of its funding with the forced exodus from Uzbekistan of the foreign funders of grants (an issue that arose from government policy and representative of an external force). The transformational leaders of the BWA involved the membership in designing a strategy to maintain a revenue stream that could sustain the association (BG03). The flat organizational structure of the association made rapid communication of the funding issue and potential solutions possible. Peer and family relationships empowered the members to identify creative solutions that were acceptable to the majority of association members. Seminars and skill building activities (services) were adjusted to maximize income potential. The four internal components of the BWA Leadership model interacted synergistically to keep the association in alignment and balanced while maintaining a constructive dialogue and respectful relationship with the government, one of the external components of the model.

Selection of the SLT provided a flexible and multifaceted model in which the themes that emerged from the data could be grouped and examined to determine the thematic influences on the BWA. Although the SLT was not a perfect fit with the results of the study, the theory did have components, or factors, in which the majority of themes and the transformational and charismatic leadership style could be merged. The flexibility of the SLT presented an opportunity for modification and creation of the BWA Leadership Model and a context for determining the implications from the study.

\section{Recommendations for Future Research}

One of the themes that emerged from an analysis of the data was Peer and Family Relationships. The importance of family support was mentioned by several respondents with only one person stated that she did not have her family's support in starting and operating her business. The results of the research were in conflict with the literature that described the Uzbek Muslim culture as seeking to limit women to the traditional role of wife and mother and not supportive of the woman working outside the home. Not only were the respondents given approval and support from their husbands and children, many family members joined the business started by the wife and mother. Further research is needed to understand if the support received from husbands and family members is a societal trend or an anomaly within the membership of the BWA and to identify the attributes, if present, of the trend or anomaly.

A second suggestion for future research is to investigate whether the BWA leadership model and the phenomenon of the viability and sustainability of the BWA is transferable to businesswomen's associations in other developing countries. A review of the literature regarding businesswomen's association in Bangladesh, China, Egypt, India, Jordan, South Korea, Tunisia, and Yemen was conducted. Commonalities in the operating environment, challenges, external forces, organizational structure, leadership style, services, and beliefs, attitudes, and values were identified (USAID, 2009), which indicated that transferability is a possibility.

\section{REFERENCES}

Alimbekova, D. M. (2002). Women entrepreneurs: Uzbekistan. Retrieved from www.unece.org/operact/ gallery/uz/uz-gal.htm

Ardichvili, A., \& Kuchinke, K. (2002). Leadership styles and cultural values among managers and subordinates: A comparative study of four countries of the former Soviet Union, Germany, and the US. Human Resource International, 5(1), 99-117. Retrieved from EBSCOhost database.

Association of Business Women of Uzbekistan. (2007). Retrieved from http://bwa.freenet.uz

Bass, B. M. (1990). Bass \& Stogdill's handbook of leadership: Theory, research, and managerial application $\left(3^{\text {rd }}\right.$ ed.). New York: Free Press.

Bass, B. M. (1998). Leadership and performance beyond expectations. New York, NY: Free Press.

Chalhoub, M. S. (2009). The effect of management practices on corporate performance: An empirical study of nongovernmental organizations in the Middle East. International Journal of Management, 26(1). Retrieved from ProQuest database.

Cooper, B., \& Traugott, I. (2003, Spring). Women's rights and security in Central Asia. World Policy Journal, 20(1), 59-67. Retrieved from ProQuest database.

Creswell, J. W. (2005). Educational research: Planning, conducting, and evaluating quantitative and qualitative research ( $2^{\text {nd }}$ ed.). Upper Saddle River, NJ: Pearson Merrill Prentice Hall.

Cron, W. L., \& Bruton, G. D. (2006). Professional service ventures, performance, and the gender effect. Journal of Leadership and Organizational Studies, 12(3), 53-67. Retrieved from EBSCOhost database.

Fraser, S. (2008). Charismatic leaders may hinder the sustainability of improvement. Retrieved from http://beermar.ecademy.com/node.php?id=101330.

Gleason, G. (2006). The Uzbek expulsion of U.S. forces and 
realignment in Central Asia. Problems of PostCommunism, 53(2), 49-60. Retrieved from EBSCOhost database.

Hartog, D. N., House, R J., Hanges, P. J., et al. (1999). Culture specific and cross culturally generalizable implicit leadership theories: Are attributes of charismatic/transformational leadership universally endorsed? Leadership Quarterly, 10(2), 219-256. Retrieved from ProQuest database.

Holtkamp, L., Irby, B. J., Brown, G., Yang, L. (2007). Validation of the synergistic leadership theory. Journal of Research for Educational Leaders, 4(1), Retrieved from http://www.education.uiowa.edu/ irel/spring07/Archive.htm

Hutchings, K. (2000). Cultural norms and gender inequality in Malaysia. Race, Gender \& Class, 7(2). Retrieved from ProQuest database.

Irby, B., Brown, G., Duffy J., \& Trautman, D. (2002). The synergistic leadership theory. Journal of Educational Administration, 40(4), 304-322. Retrieved from Emerald database.

Kamp, M. (2006). The new woman in Uzbekistan: Islam, modernity, and unveiling under communism. Seattle, WA: University of Washington Press.

Kark, R., \& Shamir, B. (2002). Untangling the relationships between transformational leadership and followers' identification, dependence and empowerment. Retrieved from www. si.umich.edu/ICOS/identifications.htm

Lucy, D. M., Ghosh, J., \& Kujawa, E. (2008). Empowering women's leadership: A case study of Bangladeshi microcredit business. S.A.M. Advanced Management Journal, 73(4). Retrieved from ProQuest database.

MacLeod, C., \& Mayhew, B. (2008). Uzbekistan. The golden road to Samarkand ( $6^{\text {th }}$ ed.). Hong Kong: Odyssey Publications.

Maksudova, N. (2009). Microfinance in Uzbekistan: Market overview and impact assessment needs. OsteuropaInstitut Regensburg, 39. Retrieved from www.microfinancegateway.org/p/site/m/template.rc/1.9.3 6534

Moustakas, C. (1994). Phenomenological research methods. Thousand Oaks, CA: Sage Publications.

Ndemo, Bng., \& Maina, F. W. (2007). Women entrepreneurs and strategic decision making. Management Decision, 45(1), 118-130. Retrieved from ProQuest database.

NGO Sustainability. (2007). The 2007 NGO sustainability index. $\quad$ Retrieved from www.usaid.gov/locations/Europe_eurasia/dem_gov./ngoi ndex/2007/Uzbekistan.pdf.

Saidazimova, G. (2005). Women \& power in Central Asia (part I): The struggle for equal rights. Radio Free Europe. Retrieved from http://www.rferl.org

Tokhtakhodjaeva, M. (2000). Traditional stereotypes and women's problems in post-Soviet Uzbekistan: A survey of the mass media. Retrieved from http://www.wluml.org/ english/pubsfulltxt.shtml?cmd[87]=i-87-2745

UNDP. (2006). Millennium development goals report. Retrieved from http://www.undp.uz/en/publicatio ns/ publication.php?id=41 and Eastern Europe and Eurasia, $12^{\text {th }}$ edition. Retrieved January 25, 2010, from www.usaid.gov/locations/ europe_eurasia/dem_gov/ngoindex/

Welter, F., Smallbone, D., \& Isakova, N. (Eds.). (2006). Enterprising women in transition economies. Burlington, VT: Ashgate Publishing Company.

Wilson, D. W., \& Washington, G. (2007). Retooling phenomenology: Relevant methods for conducting research with African American women. The Journal of Theory Construction \& Testing, 11(2), 63-66. Retrieved from EBSCOhost database.

Women Economic Empowerment (2007). The project. Retrieved from http://www.womensilkroad.com

World Population Prospects: The 2006 Revision and World Urbanization Prospects (2006). The 2005 Population Division of the Department of Economic and Social Affairs of the United Nations Secretariat. Retrieved from http://esa.un.org 


\section{ABOUT THE AUTHORS}

Corresponding author: Dr. Kimberly Millier, email: jkmconsult@gmail.com

Dr. Kimberly Millier is a doctoral chair at Grand Canyon University and instructs at the doctoral level. Dr. Millier received her Doctor of Business Administration from the University of Phoenix School of Advanced Studies in 2010. Since 1991, she has conducted research and provided training throughout the Central Asian Republics and worked closely with the Business Women's Association (Tadbikor Ayol) of Uzbekistan. Dr. Millier has published several peer-reviewed articles and briefs focused on Central Asia and the role of women in the region.

Dr. Patty-Jo Bellamy is an adjunct instructor in management for Kaplan University. Dr. Bellamy received her Doctor of Business from the University of Manitoba, Canada in cross-cultural consumer behavior. Since 1995 she has conducted research in the impact of values on communication and cross-cultural studies. She has conducted research with both Asian and North American cultures. She continues to focus on cultural differences in values, communication and behaviors. 